\title{
Rules of Origin for Preferential Trading Arrangements: Implications for the ASEAN Free Trade Area of EU and US Experience
}

\author{
Olivier Cadot \\ University of Lausanne \\ Jaime de Melo \\ University of Geneva
}

\begin{abstract}
Alberto Portugal-Pérez
University of Geneva
\end{abstract}

\begin{abstract}
With free trade areas (FTAs) under negotiation between Japan and the ASEAN Free Trade Area (AFTA) members and between the Republic of Korea and AFTA members, preferential market access will become more important in Asian regionalism. Protectionist pressures will likely increase through rules of origin, the natural outlet for these pressures. Based on the experience of the European Union and the United States with rules of origin, this paper argues that, should these FTAs follow in the footsteps of the EU and the US and adopt similar RoO, trading partners in the region would incur unnecessary costs. Using EU trade with GSP and ACP partners, the paper estimates how the utilization of preferences would likely change if AFTA were to veer away from its current uniform RoO requiring a $40 \%$ local content rate. Depending on the sample used, a 10 percentage point reduction in the local value content requirement is estimated to increase the utilization rate of preferences by between 2.5 and 8.2 percentage points.
\end{abstract}

- JEL classification: F13, F15

\footnotetext{
*Corresponding address: Olivier Cadot, University of Lausanne, CERDI and CEPR: E-mail: cadot@ hec.unil.ch, Jaime de Melo, University of Geneva, CERDI and CEPR: E-mail: DeMelo@ecopo.unige.ch, Alberto Portugal-Pérez, University of Geneva,: E-mail: Alberto.Portugal@ecopo.unige.ch (C)2007-Center for International Economics, Sejong Institution, All Rights Reserved.
} 
- Keywords: Rules of Origin, Preferential Trade Agreements, Market Access, NAFTA, PANEURO, AFTA, ASEAN.

\section{Introduction}

Rules of Origin (RoO) are integral to the proliferating Free Trade Areas (FTAs) or the non-reciprocal Preferential Trading Arrangement (PTAs) such as the Generalized System of Preferences (GSP). RoO are necessary in any PTA to prevent trade deflection, by which is meant that the country with the lowest external tariff acts as port of entry for the entire bloc's imports, depriving partners of tariff revenue. RoO are about to become important in the trade policy landscape in Asia as at least 45 but up to 70 discriminatory trade deals will be in existence at the end of 2006.

Typically RoO are defined at the HS-6 tariff level. However, the Harmonized System (HS) was not designed as a vehicle for conferring origin, its purpose being to provide a unified commodity classification for defining tariff schedules and for the collection of statistics. As a result, devising methods for determining sufficient processing or substantial transformation has turned out to be very complex in all existing PTAs, notably for the two big players, the EU and the US, which use three categories of criteria to determine if sufficient transformation has taken place in activities that require processing: (i) change of tariff classification; (ii) a critical threshold for value-added (in short a 'value content' (VC) rule); and (iii) specific manufacturing processes.

Currently under AFTA, ASEAN - China Free Trade Area (ACFTA) and the other regional Asian FTAs under negotiation involving the Korea and Japan, bilaterals with ASEAN nations, to obtain originating status (i.e. to fulfill the criterion of sufficient processing), either of two criteria is used. The" wholly obtained" criterion is used for a few agricultural products. For the vast majority of products, a single value content rule requiring that at least $40 \%$ of the value of the final product must originate from the countries belonging to the FTA (i.e. nonoriginating imports cannot exceed $60 \%$ of the value of the final product) is used in combination with diagonal cumulation (see below). This criterion is remarkably simple compared with the criteria described here which are used notably by the two major players, the EU and the US. ${ }^{1}$ This paper argues that it should be kept so.

'The EU uses such a RVC rule-only for $11.46 \%$ of its tariff lines, while the US does not use any RVC rule-only. 
However, keeping the present simple system might prove to be difficult because intra-regional trade is likely to rise sharply as the economies integrate. Given the limits to other forms of protection imposed by WTO membership, the candidate outlet for rising protectionist pressures could be a move towards a complex system of RoO ('the US and the EU did it, so why shouldn't we follow in their footsteps!').

East Asia is now entering a phase of very active regional integration. That integration will certainly extend beyond preferences in goods trade with a rich variety of expected gains from regional integration (see e.g. Antkiewicz and Whalley (2004), and Banda and Whalley (2005)). However, in spite of substantial unilateral tariff reductions, preferential market access will still be a key component of that regionalism. With preferential market access on the rise, and with more trade taking place regionally, the adoption of complex product-specific RoO (PSRO) could turn out to be key in the negotiations of tariff elimination among trading partners. Thus with trade conflicts likely to occur in the region as the volume of trade continues to increase, this conflict could largely play out in RoO, a trade policy instrument that has so far eluded any discipline from the World Trading System. With the large number of trading arrangements under way, it is very plausible that lobbying activities will resemble those in other PTAs like those involving the US and EU with lobbies in the most powerful partners managing to justify 'made-to-measure' RoO to maximize rent-extraction to their benefit at the expense of the weaker partners.

This paper argues that a move in that direction should be avoided. It does so by presenting evidence on the costs of the complex RoO put in place by the EU and the US on their trading partners. Indeed, the experience with RoO elsewhere shows that $\mathrm{RoO}$ diminish the value of preferences, in effect reducing the market access that the preferences are intended to provide in the first place beyond what would appear to be "sufficient" transformation to confer "legitimate" origin. Hence, the main message of the paper for the AFTA partners is to avoid the (tempting) trap of moving towards more complex RoO resembling those observed in other preferential trading agreements (PTAs). To use a well-worn expression, RoO should be "business friendly" rather than "business owned".

The paper is organized as follows. Section 2 details the RoO of the EU (these are the rules that AFTA countries must comply with to benefit from the GSP) and those under NAFTA (a variant of these have been adopted in other FTAs involving the US). Section 3 discusses the economics of RoO and what we learned about the effects of RoO from NAFTA and the US experience. Section 4 presents new 
results that should be of use for AFTA. Exploiting data on tariff lines where a minimum regional $\mathrm{VC}$ is the sole criterion for establishing origin, we estimate utilization rate responses to changes in preference margins and in the stringency of the VC rule. Section 5 concludes.

\section{Rules of Origin in US and EU PTAs}

With the exception of AFTA (and a few others like ANZERTA and ANZSCEPsee Table A1), RoO in PTAs have two components: a regime-wide set of rules and product-specific rules of origin (PSRO). These are described in the annex where Table A1 lists the regime-wide rules and Table A2 the PSRO criteria negotiated between Mexico and the US in the context of NAFTA and the so-called PANEURO single-list regime used by the EU in all its PTAs. Table A1 confirms that AFTA has a much simpler set of criteria, since it relies only on a minimum share of originating value among partners (which is equivalent to maximum value of non-originating imports). ${ }^{2}$ Of course, this minimum originating $\mathrm{VC}$ applies at the product level so in a sense it is also a PSRO but because it is uniform, in effect it is a level-playing field and AFTA does not have PSRO. The EU also uses the $\mathrm{VC}$ criterion extensively, though most often this criterion is used along with other criteria (see Table 1 and Table A2).

For AFTA, the VC rule is also its regime-wide rule. AFTA, like the EU PTAs, also provides for diagonal cumulation which is less stringent than the more usual bilateral cumulation rule applied in the PTAs described in Table A1. Under diagonal cumulation, countries tied by the same PTA can use materials that originate in any member country as if the materials were originating in the country where the processing is undertaken. ${ }^{3}$ However, since the domestic content can be an aggregate of value-added in any ASEAN member state, AFTA provides in effect for full cumulation although, as noted by Brenton (2006), the rules stipulate that the final stage of manufacture must be carried out in the exporting member state (what constitutes 'the final process' is not defined). Because vertical linkages and outsourcing are very important in Asia (see below), full cumulation relaxes

\footnotetext{
${ }^{2}$ More precisely, the RoO requires that the non-originating import content be less than 60 percent of the FOB price of the product where the value of non-originating materials is based upon the CIF import price or the earliest ascertained price for products of undetermined origin.
}

${ }^{3}$ See the appendix for a definition of bilateral, diagonal and full cumulation. 
Table 1. Distribution of PSRO under NAFTA and PANEURO

\begin{tabular}{|c|c|c|c|c|c|c|c|c|c|c|c|c|c|c|}
\hline \multirow[t]{2}{*}{$\begin{array}{c}\% \text { of tariff } \\
\text { lines }\end{array}$} & \multicolumn{2}{|c|}{$\begin{array}{l}\text { "No other } \\
\text { requirement" or } \\
\text { "EXC" }\end{array}$} & \multicolumn{2}{|c|}{$\begin{array}{c}\text { "TECH" } \\
\text { or } \\
\text { "TECH+EXC" }\end{array}$} & \multicolumn{2}{|c|}{$\begin{array}{c}\mathrm{VC} " \\
\text { or } \\
\text { "VC+EXC" }\end{array}$} & \multicolumn{2}{|c|}{$\begin{array}{c}\text { "TECH+VC" } \\
\text { or } \\
\text { "TECH+VC+EXC" }\end{array}$} & \multicolumn{2}{|c|}{$\begin{array}{l}\text { "Wholly obt'd" } \\
\text { (WH) }\end{array}$} & \multicolumn{2}{|c|}{ Other addit. Requir. } & \multicolumn{2}{|c|}{ SUBTOTAL } \\
\hline & NAF & PAN. & NAF. & PAN. & NAF. & PAN. & NAF. & PAN. & NAF. & PAN. & NAF. & PAN. & NAF. & PAN. \\
\hline No CTC & 0.5 & 0.6 & 0.0 & 2.6 & 0.0 & 13.0 & 0.0 & 0.2 & 0.0 & 8.1 & 0.0 & 7.0 & 0.5 & 31.5 \\
\hline CI & 0.0 & 0.0 & 0.0 & 0.0 & 0.0 & 0.0 & 0.0 & 0.0 & 0.0 & 0.0 & 0.0 & 0.0 & 0.0 & 0.0 \\
\hline CS & 3.8 & 0.1 & 0.4 & 0.0 & 0.1 & 0.4 & 0.0 & 0.0 & 0.0 & 0.1 & 0.0 & 0.4 & 4.4 & 1.0 \\
\hline $\mathrm{CH}$ & 36.3 & 16.5 & 0.2 & 7.8 & 4.1 & 12.8 & 0.1 & 0.1 & 0.0 & 0.3 & 0.0 & 13.9 & 40.7 & 51.3 \\
\hline $\mathrm{CC}$ & 48.7 & 0.0 & 5.8 & 7.3 & 0.0 & 0.0 & 0.0 & 0.1 & 0.0 & 0.0 & 0.0 & 0.2 & 54.4 & 7.7 \\
\hline Altern. & & & & & & & & & & & & 8.7 & 0.0 & 8.7 \\
\hline Total & 89.3 & 17.2 & 6.4 & 17.7 & 4.2 & 26.1 & 0.1 & 0.4 & 0.0 & 8.5 & 0.0 & 30.1 & 100 & 100 \\
\hline
\end{tabular}

Notes:

Classification is carried out at the HS-6 tariff line level (\#5595 lines for the EU and \# 3995 for NAFTA). Each cell is the percentage of tariff lines that have the $\mathrm{RoO}$ in the corresponding row and in the corresponding column.

$\mathrm{CTC}=$ change in tariff classification with $\mathrm{CC}=$ Change in Chapter $/ \mathrm{CH}=$ Change in Heading $/ \mathrm{CS}=$ Change in Subheading $/ \mathrm{CI}=\mathrm{Change}$ in Item;

$\mathrm{EXC}=$ Exception to change of tariff classification;

$\mathrm{VC}=$ Regional Value Content; TECH = Technical Requirement.

Altern. $=$ Lines for which importers can choose between alternative criteria.

Source: Cadot et al. (2006b), Table 2 
Table 3. Protection, the PSRO Restrictiveness Index, and Utilization rates in Textiles and Apparel

3a. Tariff Peaks and the PSRO index

\begin{tabular}{|c|c|c|}
\hline & \multicolumn{2}{|c|}{ R-Index value $e^{\mathrm{a}, \mathrm{b}}$} \\
\hline & $\overline{\text { NAFTA }}$ & PANEURO \\
\hline Tariff peaks ${ }^{\mathrm{c}}$ & $6.2(257)$ & $5.18(780)$ \\
\hline Low tariffs $\mathrm{s}^{\mathrm{d}}$ & $4.8(1432)$ & $3.92(3241)$ \\
\hline Total number of tariff lines & 3555 & 4961 \\
\hline
\end{tabular}

a/ Source. Cadot et al. (2006b), table 3. ${ }^{\mathrm{b}} \mathrm{RoO}$ indexes are unweighted indexes.

c,d /Tariff peaks (low tariffs) are calculated for all tariff lines that exceed 3 times (one third of) the average GSP tariff level.

3b: Preferences and Utilization Rates in Textiles \& Apparel (HS-11) (averages, unweighted)

\begin{tabular}{|c|c|c|c|}
\hline & \#Observations ${ }^{\mathrm{e}}$ & Utilization rate & Preferential Margin \\
\hline NAFTA (2001) & 618 & 79.9 & 10.4 \\
\hline GSP (2004) & $\begin{array}{l}16555 \text { (HS-8) } \\
12920 \text { (HS-6) }\end{array}$ & 52.2 & 1.8 \\
\hline ACP (2004) & $\begin{array}{l}1370 \text { (HS-8) } \\
1175(\text { HS-6) }\end{array}$ & 50 & 10.4 \\
\hline
\end{tabular}

considerably the requirements of satisfying origin. Thus under full cumulation, the more developed higher labor cost countries can outsource labor-intensive, lowtech, production stages to less developed lower-wage partners whilst maintaining the preferential status of the good produced in the low-cost locations.

Table 1 tabulates the criteria used for PRSO under PANEURO and NAFTA. It shows that the two regimes use a large list of criteria. These typically include technical requirements (such as the triple transformation requirement in textiles and apparel which requires that apparel must be woven from originating fabric and from originating yarn). The criteria also include exceptions and allowances. NAFTA relies more heavily on a change of tariff classification (CTC), though often accompanied by other criteria. PANEURO relies mostly on a VC and on the Wholly obtained (WH) criterion (this criterion is not used in NAFTA since Mexicans export far fewer agricultural exports than GSP and ACP countries).

The key issue is how RoO affect the utilization of preferences (i.e. do importers end up using the MFN status when preferences would suggest they should claim for preferential status)? Table 2 and Figure 1 show average utilization rates computed for different thresholds of minimum preferential margins for NAFTA and for the two EU preferential schemes, the Generalized system of preferences (GSP) for which ASEAN countries (except Singapore qualify) and the Cotonou 
Figure 1. Average utilization rates for different thresholds of preferential margin rates ${ }^{\mathrm{a}}$

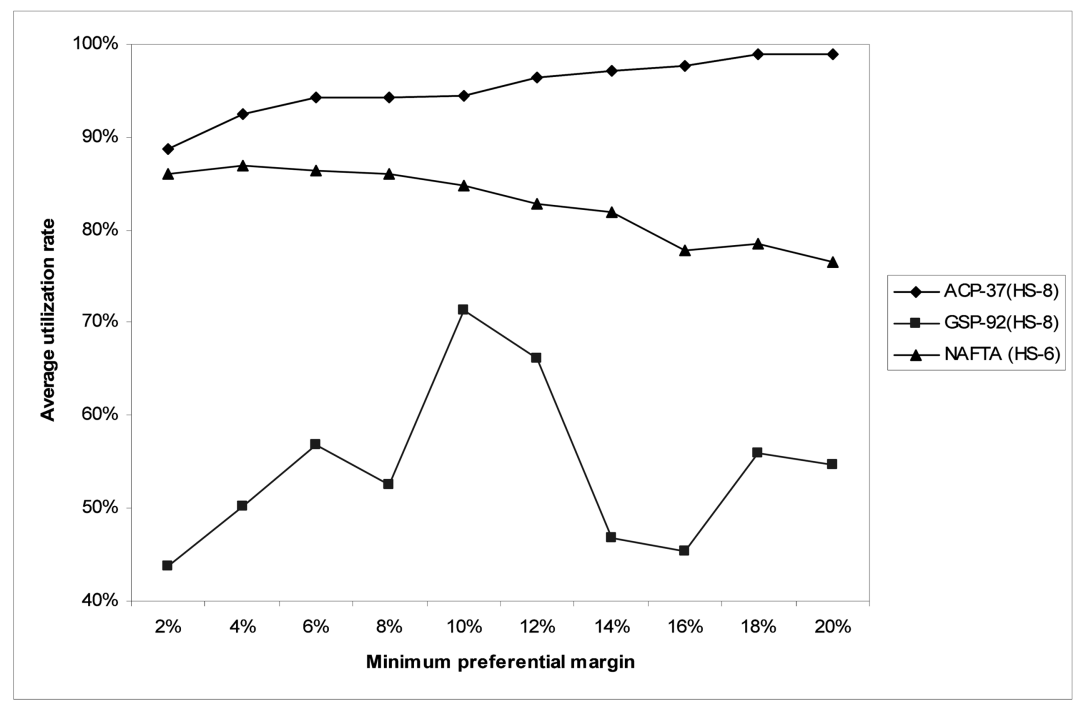

a Unweighted averages computed at the most disaggregated tariff line level (see Table 2). Averages based on over 100 observations except for GSP (minimum of 27 observations for $\tau_{i} \geq 20 \%$ )

Table 2. Preferences and their utilization in the NAFTA and EU market(un-weighted data)

\begin{tabular}{cccc}
\hline & $\operatorname{GSP}(92)^{\mathrm{b}}$ & $\operatorname{ACP}(37)^{\mathrm{b}}$ & NAFTA $^{\mathrm{c}}$ \\
\hline$\tau \geq 4 \%^{\mathrm{a}}$ & $50.2 \%(1297)^{\mathrm{d}}$ & $92.5 \%(1627)^{\mathrm{d}}$ & $87.0 \%(1239)^{\mathrm{d}}$ \\
$\tau \geq 8 \%^{\mathrm{a}}$ & $52.5 \%(91)$ & $94.3 \%(892)$ & $86.0 \%(558)$ \\
$\tau \geq 12 \%^{\mathrm{a}}$ & $66.2 \%(44)$ & $96.4 \%(566)$ & $82.8 \%(287)$ \\
\hline
\end{tabular}

a $\tau_{i}=\left(t_{i}^{M F N}-t_{i}^{P R E F}\right) /\left(1+t_{i}^{P R E F}\right)$ is the preference margin.

${ }^{\mathrm{b}}$ Computed at the HS-8 tariff line level for GSP and ACP.

${ }^{\mathrm{c}}$ Computed at the HS-6 tariff line level for NAFTA.

${ }^{\mathrm{d}}$ Number of tariff lines between brackets.

Source: Authors' calculations

preferences which benefit the former colonies of the Africa, Caribbean and Pacific (ACP) regions. ${ }^{4}$ Since there are administrative costs (see below), only utilization rates above $4 \%$ are considered in Table 2 which also shows in parenthesis the

\footnotetext{
${ }^{4}$ The reason for distinguishing between GSP and ACP utilization rates is that ACP preferences have been in effect longer, that all tariff lines qualify for ACP status, that some GSP-eligible countries also qualify for EBA but have chosen not to use the more favorable status, perhaps because these preferences were only in effect since 2002 or finally because of slightly more stringent regime-wide rules for GSP-eligible countries than for ACP countries. Also all AFTA countries except Singapore qualify for GSP status.
} 
number of tariff lines over which utilization rates are computed.

As a reference, the average preferential margin (computed over tariff lines with positive tariffs) was $4.5 \%$ for NAFTA (almost all tariffs had been eliminated on NAFTA trade by 2001), 2.4\% for GSP-eligible countries and $4.6 \%$ for ACP countries (not eligible for EBA status). EU data is for 2004, when $62 \%$ of trade for GSP-eligible countries took place at zero tariffs and over 80\% for ACP countries (some ACP also benefiting from EBA status at zero tariffs in the EU market).

Several patterns stand out. First, utilization rates by Mexican exporters are systematically higher than utilization rates by eligible exporter to the EU's GSP. This could reflect several factors including closer proximity and knowledge of the US market, but also less stringent RoO rules or greater administrative costs for EU schemes than for NAFTA (e.g. relating to certification methods). ${ }^{5}$ The differences in utilization patterns also probably reflect partly differences in the composition of exports.

Second, utilization rates are systematically higher for ACP countries than for GSP countries (this is why the number of tariff lines is always greater for ACP countries than for GSP countries at any tariff line, even though there are fewer ACP (78) than GSP (92) countries). ${ }^{6}$ Again, it could be that better knowledge of procedures (same language for former colonies) are a factor, but the combination of higher preference margins and better market access due to less stringent rules of origin must also be a determining factor. Regarding RoO, the regime-wide rule for ACP countries are less restrictive that for GSP qualifiers since they benefit from full cumulation rather than diagonal cumulation and they have a more favorable tolerance rule ( $15 \%$ tolerance for all tariff lines instead of $10 \%$ and an exclusion of access to the tolerance rule for chapters 50 to 63 which cover textiles and apparel (T\&A) for the group of 92 GSP-eligible countries).

Third, as can be seen from Table 2 and Figure 1, utilization rates do not rise monotonically with preference margins, as one would expect. Indeed, utilization rates fall as preference margins increase for NAFTA and also for the GSP-eligible

\footnotetext{
${ }^{5}$ For example, under NAFTA certification is carried out by the private sector and does not have to be carried out for each transaction, whereas under PANEURO regime there is a double certification method (private and public) for each transaction. See Estevadeordal and Suominen (2006) for further discussion and comparison of certification methods across PTAs.

${ }^{6}$ Of the 78 ACP countries, 41 qualify for Everything But Arms (EBA) status which gave these countries virtually duty-free access to the EU market. However, in 2004, most ACP countries qualifying for EBA status continued to request ACP status. Hence when we speak of ACP countries, we refer to the $78 \mathrm{ACP}$ countries.
} 
Figure 2. Growing Vertical integration in the World Economy

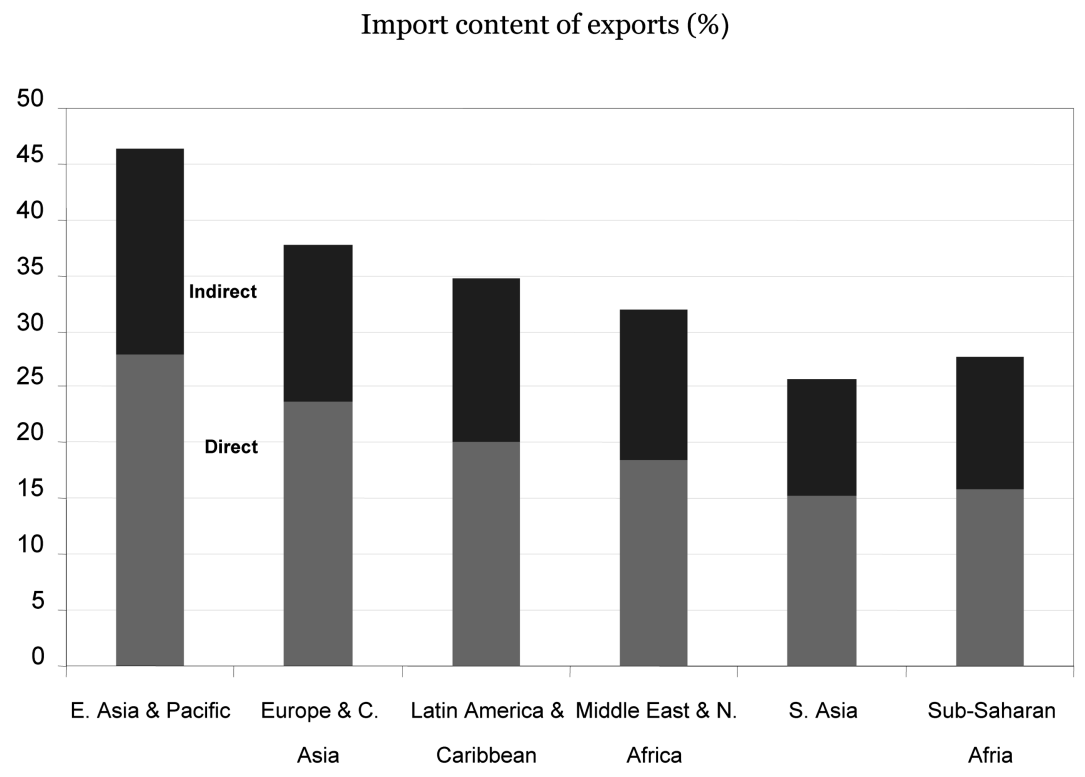

Sources : WB (2005), GEP, figure 3.1

countries over a certain range. This is due to a composition effect. In the T\&A sector where preference margins are around or above $10 \%$, utilization rates are low. However. GSP-eligible countries get much less preferential access than ACP countries in the T\&A sector (see Table $3 b$ ). Since these sectors are characterized by specific manufacturing requirements, lobbying activities by the domestic industries in the high-income partner influence the specification of the rules, and the utilization rates are low even though preferential margins are high. ${ }^{7}$ Based on an analysis of utilization rate in that sector for NAFTA, Anson et al. (2005) and Cadot et al. (2005 and 2006a), conclude that the PSRO requirements in that sector were designed to leave Mexican exporters on their 'participation constraint', i.e. leaving only marginal rents for Mexican exporters.

Are these utilization rates low? Certainly not by AFTA standards which show utilization rates in the 5\%-10\% range for the late 1990s for the Philippines, the

\footnotetext{
${ }^{7}$ Brenton and Imagawa (2005, Box 9.2, p. 20) mention a particularly egregious case in which NAFTA's RoOs for apparel specify that imported fabric must be "of subheading 511111 or 511119 , if hand-woven, with a loom width of less than $76 \mathrm{~cm}$, woven in the United Kingdom in accordance with the rules and regulations of the Harris Tweed Association, Ltd, and so certified by the Association". Such specific rules, which clearly smack of firm-specific lobbying are, however, relatively uncommon.
} 
country with the highest preference utilization rate (see Baldwin (2006), Figure 5). Baldwin argues that this is because the bulk of intra-ASEAN trade is in the computer/machinery (HS-84) and electrical equipment (HS-85) sectors where preferential access market is negligible. However, the use of a VC criterion could also contribute to this low rate of utilization of preferences even if at first sight meeting this requirement would not appear to be too difficult since most parts are indeed produced in the region, at least for the computer hard-disk example shown in his Figure 8. However, the very high import content of exports for the Asia region shown in Figure 2 suggest that AFTA utilization rates could be low under the present VC limit.

To drive home the importance of trade in intermediates, consider the following example recalling that Japan is not currently a member of AFTA. According to the Asian input-output data provided in Baldwin (2006, Table 1), for all the middleincome countries (Indonesia, Philippines, Malaysia, Thailand), on average 35\%$40 \%$ of intermediates are sourced from outside the AFTA group. Take then an activity with a $10 \%$ value-added (this value-added Figure is consistent with the deepening of inter-industry flows) and $40 \%$ intermediates non-originating. Then, originating value for this activity would be, $64 \%$. But for activities where $60 \%$ of materials would be non-originating, originating value would fall to $46 \%$, barely above the stipulated $40 \%$ minimum requirement stipulated under AFTA. One might also note that, in the case of the EU, the preference rate for tariff lines where a value-content only criterion is used is lower than for the other tariff lines (see Table 5) .

Returning to the EU and US PTAs, the rather low utilization rates for relatively high preference margins suggests that restrictive PRSO could be the culprit. Indeed, it could well be that more restrictive PSRO are applied to the tariff lines with the highest preferential margins. To see if this is the case, we use an ordinal restrictiveness index that takes values in the range $1 \leq r_{i} \leq 7$ with increasing values corresponding to a more restrictive rule. ${ }^{8}$ Though not amenable to quantification like effective rates of protection, the R-index is intended to play the same role as an

\footnotetext{
${ }^{8}$ The index was first proposed by Estevadeordal (2000) for NAFTA. The construction of the R-index is illustrated in the appendix and discussed in further detail in Cadot et al. (2006). In addition to the inevitable arbitrariness involved in setting up the observation rule, the R-index has other shortcomings. In particular, it does not control for the degree of preferences and for the characteristics of the different activities: satisfying a CTC involving a $\mathrm{CH}$ for intermediate activities is likely to be easier than if it is to be satisfied for a final good activity. Finally, it is an ordinal rather than cardinal measure. For a description of some of the shortcomings of the R-index, see Erasmus et al. (2006).
} 
effective rate of protection: indicate the restrictiveness that must be met by a product to obtain originating status. Table 3 a shows that tariff lines with tariff peaks (tariffs lines three times or more the average tariff) that is tariff lines where preferential margins are the highest do indeed have a higher value for the R-index than those with low tariffs. This is the case for both NAFTA and the EU.

The conclusion from this first look at preferential margins and utilization rates is that, even for non-negligible preferences, utilization rates can be quite low, and that PSRO are, at least partly, designed to discourage the use of preferences. This is particularly true for the T\&A sector where multiple criteria are the norm.

Once more, one might ask how relevant these observations are for AFTA. At this stage almost all intra-ASEAN trade is in 'middle-products' (see Sanyal and Jones (1982), the final product being sold to the outside world. But the picture would change rather dramatically with the proposed FTAs between Japan and AFTA members and between Korea and other AFTA members. Then, the resulting pattern of trade would be closer to the one currently observed between the US and the EU and their Southern trading partners. Here, differences in endowments matter with the resulting pattern of trade being of the inter-industry rather than intra-industry pattern. As soon as inter-industry trade involves the sourcing of a fraction of intermediates from the outside world and there is potential for regional trade in the final product (e.g. in apparel and other light industry products), the experience of the EU and US becomes relevant.

East Asian trade has grown remarkably rapidly in the last 15 years through the breaking up of the manufacturing process or the 'slicing up of the value chain'. With tariff cuts on a discriminatory basis in the China-ASEAN FTA and the JapanASEAN bilaterals on the table, tensions are likely to appear in the region. One likely element of these tensions will be the negotiation over Rules of Origin (RoO).

So why are RoO in AFTA apparently less stringent than elsewhere? First, until recently Asian regionalism has been more about cooperation than about preferential trade (APEC under the aegis of the US was specifically set up to avoid preferential trade and the formation of an 'Asian trade bloc'), with much of the Region's integration in the world economy driven by unilateral tariff reductions. Second, much of the regional trade has been part of the development of the 'Asian manufacturing matrix' whereby the labor-intensive stages of production initially carried out in Japan and then Korea have been outsourced to the lower-wage countries in the region for final exporting to the EU and US markets. In this unusual set-up relative to the other global trading patterns, intra-regional trade in 
politically sensitive final products where protection is highest was insignificant. Hence, the political-economy forces that would usually lead to lobbying activity resulting in the complex RoO observed elsewhere was not observed.

\section{The Economics of RoO}

RoO are often justified as an instrument to promote industrialization in lowincome countries (or value-added-generating activities). In fact, they impose costs on the intended beneficiaries of preferences. In addition, contrary to what is claimed, rather than help countries industrialize, they end up suppressing trade, an effect that could be particularly important in AFTA countries where much fractionalization of production takes place (Erasmus et al. (2006) provide vivid examples based on case studies in SADC where RoO have been claimed to be a development tool for low-income members).

The suppression effect of RoO can be easily visualized if one considers that the production of a final product involves a continuum of activities, with the range of activities being ordered in decreasing labor-intensity. For example the sowing of buttons on a shirt could take place in low-income Cambodia, the weaving in Indonesia, the production of yarn in Indonesia. Then imposing a minimum regional VC would suppress trade with the outside partner (Bangladesh) and redirect investments to the region. As a result, production costs would increase and efficiency would fall.

Below we present a general decomposition formula of the costs of RoO using a minimum VC. This decomposition motivates the review of evidence that follows and serves a justification for the new estimates presented in section 4 .

\section{A. The Costs of RoO: a decomposition}

Suppose that a producer in the Philippines wishes to sell a shirt, $X_{i}$, under preferential access in another AFTA member, Thailand. This shirt is produced with 'originating' intermediate goods (i.e. with intermediates from other AFTA members and from domestic sources), $Z_{j}^{0}$, but also with inputs from nonoriginating sources, $Z_{j}^{N}$, say from Bangladesh or India. Let $i$ stand for the shirt and $j$ for the intermediates, say textiles. Omit any taxes paid domestically, and label each input with its own price since intermediates are differentiated products. Let $V A_{i}$ represent the payments to labor (and to capital or profits). Then the value of final sales is broken down between payments to value added and to intermediate products: 


$$
P_{i} X_{i}=V A_{i}+P_{j}^{O} Z_{j}^{O}+P_{j}^{N} Z_{j}^{N}
$$

To obtain originating status, intermediate purchases from domestic producers of textiles and from textile producers in the regional partner countries are counted as 'originating' i.e. $P_{j}^{O} Z_{j}^{O}$ counts as regional value-added. Then, unrestricted originating value-added expressed as a percent of unit sale (evaluated at FOB prices in the case of AFTA) is given by the expression:

$$
v a_{i}^{*}=\left(V A_{i}+P_{j}^{O} Z_{j}^{O}\right)^{\prime} P_{i} X_{i}
$$

Now assume that to satisfy origin requirements to sell under preferential status in Thailand, the producer in the Philippines is forced to source more originating inputs than he would under optimal circumstances (i.e. in the absence of the PSRO). If we let an “*” denote the initial unconstrained (i.e. optimal) choice, and a "c" a constrained choice, then modeling the effects of a binding value content boils down to modeling the implications of:

$$
v a_{i}^{c}>v a_{i}^{*}
$$

In the case of AFTA, $\left(v a_{i}^{C} \geq 40 \%\right)$ is the uniform criterion used to qualify for originating status (although producers also have the option of using other qualifying requirements, notably in the T\&A sector where the alternative PSRO were used because the value-content rule was found to be too restrictive).

Figure 3, adapted from Krishna (2006) shows the costs implications of forcing a producer to use more originating inputs than he would otherwise. Assume a competitive environment with a constant- returns-to- scale technology where the producer who takes his cost-minimizing decision on the basis of given prices. When he is unconstrained in his purchase of intermediates, (i.e. when $\left.z \equiv\left(z^{R O W} / z^{A F T A}\right)=z^{*}\right)$, his unit costs are given by $c=c_{0}$. When he is constrained (i.e. when $z=z^{C}$ ), his unit costs are higher and given by $c=c_{1}$.

Being forced to use a greater share of originating inputs is equivalent to forcing him physically to use a greater proportion of originating intermediates. As a result his unit costs of production increase to $c_{1}$. Let $c_{i}^{D}\left(=c_{i}^{1}-c_{i}^{0}\right)$ be the cost induced by this distortion.

To this, one must add administrative costs, $c_{i}^{A}$. Though not shown in Figure 3 to save space, it would be easy to do so in a similar framework by reinterpreting the 
Figure 3. Rule of Origin and Costs

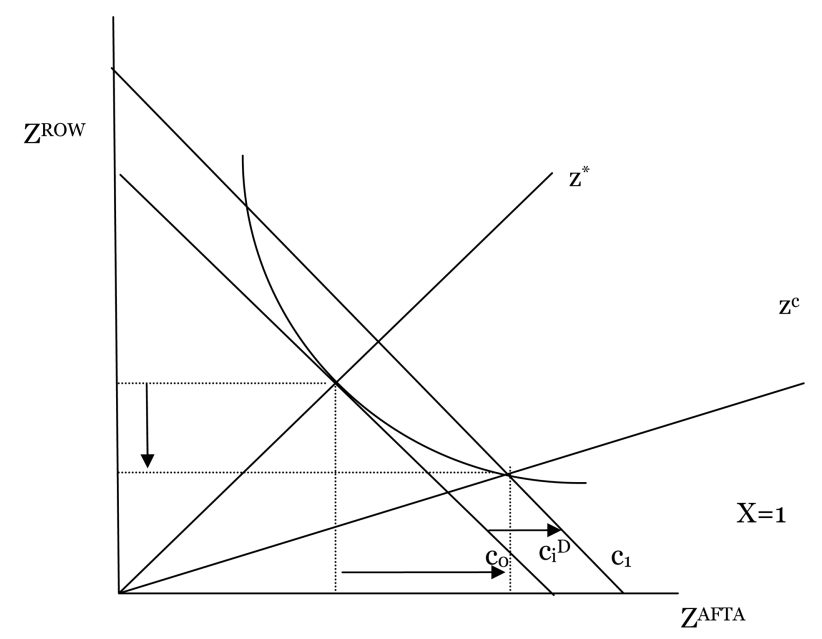

isoquant as an isovalue (i.e. it is drawn to reflect a constant value of output). Let then $P_{i}=\bar{P}_{i}^{*}=1$ and choose the constant value, $v_{i}^{0}$ so that $v_{i}^{0}=\bar{P}_{i}^{*} X_{i}=1$. With zero profits, unit costs will equal unit value $v_{i}^{0}=c_{i}^{0}$ and the producer will produce $X=1$ in equilibrium. With the product price unchanged, the effect of an increase in unit production costs is to make the producer unprofitable, unless he is compensated by sufficient preferential market access.

Finally, consider rents and market power. Recent estimates reviewed below also indicate that only a fraction of the rent associated with market access accrues to exporters and that the share of rents they receive is lessened by the presence of RoO. Call $\mu_{i}$ the loss of rent transfer associated with RoO, $\mu_{i}$. Then per unit production cost in the presence of RoO will be the sum of costs in the absence of RoO and compliance costs, $c_{i}^{C}$ :

$$
c_{i}=c_{i}^{0}+c_{i}^{D}+c_{i}^{A}+\mu_{i}=c_{i}^{0}+c_{i}^{C}
$$

Under these conditions, the Philippine producer can either export to Thailand under the Common Preferential Extended Tariff (CPET) scheme where the preferential tariff rate will be given by:

$$
\tau_{i}=\frac{t_{i}^{M F N}-t_{i}^{P R E F}}{1+t_{i}^{M F N}}
$$


or under MFN status. Under MFN status, unit price will be 1 and under preferences, $1+\tau_{i}$. Since unit profits are given by $\pi_{i}=P_{i}-c_{i}$, if $u_{i}$ denotes whether or not CPET preferential status is requested:

$$
\begin{aligned}
& \tau_{i} \geq c_{i}^{D}+c_{i}^{A}+\mu_{i} \Rightarrow u_{i}=1 \\
& \tau_{i}<c_{i}^{D}+c_{i}^{A}+\mu_{i} \Rightarrow u_{i}=0
\end{aligned}
$$

In practice, many heterogeneous firms export at the HS-8 level. Thus one will observe a distribution of utilization rates at the most disaggregated HS- 8 level. Since there is no data to match firms with utilization rates, the estimation of utilization rates and their correlates in effect assumes that all firms exporting at the HS-8 level are in effect, identical. This evidence is now reviewed.

\section{B. Evidence on the Costs of RoO}

It is difficult to estimate the costs associated with RoO because these costs are not observable. Estimating the costs of RoO is further complicated by the fact that, with the exception of the estimates presented in section 4 below, all econometric estimates so far have been obliged to rely on dummy variables to capture the presence of a $\mathrm{RoO}$ requirement (i.e. one can only note the presence or the absence of, say, an exception or a technical requirement). Finally, data on utilization rates are only available for NAFTA (and more recently for the EU preferential schemes). As a result, statistical evidence relates to the EU and US schemes, and furthermore it is partial. Below are the highlights of the econometric evidence.

\section{Distortionary Costs}

Most of the evidence rests on isolating the effects of various PSRO criteria on utilization after controlling for the influence of preferential margins. Carrère and de Melo (2006) assume that the utilization of preferences for product line $i$ is a positive function of the difference between the tariff preference margin, $\tau_{i}$, and (unobserved) total compliance costs, $c_{i}$ (expressed as a percentage of unit price) associated with applying the RoO criteria. That is they suppose that. $u_{i}=f\left(\tau_{i}-c_{i}\right) ; f^{\prime}()>$.0 , and that $c_{i}=g\left(R o O_{i}\right) g^{\prime}()>$.0 . These assumptions lead to an estimable relation of the form:

$$
u_{i}=\lambda+\alpha \tilde{\tau}_{i}+\sum_{k} \theta_{k} R o O_{i k}+\varepsilon_{i}
$$


where $R o o_{i k}$ is a vector of dummy variables capturing the presence of PSRO (technical requirements, change of tariff classifications, exceptions). Results from estimating on data from NAFTA by the authors (and by Cadot et al. (2006a) for the EU) indicates that utilization rates are positively related to preferential margins, and negatively to the presence of PSRO. Carrère and de Melo combined their estimates with R-index values to compute an estimated ad-valorem equivalent of total RoO compliance costs (administrative and due to higher input costs). Their estimates range from $3.5 \%$ for a change of chapter to over $15 \%$ for combinations of RoOs involving technical requirements.

Even if the estimates point in the same direction, it is difficult to gather a sense of robustness from estimates derived from a relation like (0.6). The reason is that there is so much heterogeneity and unobservables influencing preference uptake that estimates are quite sensitive to the inclusion of dummy variables controls (this is especially the case for estimates based on GSP preferences extended by the EU to many trading partners).

This said, all estimates point in the same direction. When multiple criteria are used to determine origin, utilization rates are, ceteris paribus lower. Moreover, results based on estimates regressing utilization rates on dummy variables capturing the presence of different types of PSRO, suggest that technical requirements tend to be associated with high compliance costs, whereas changes of tariff classification, even at high degrees of aggregation (like a change of chapter) do not seem to have comparably strong effects. Of course these suggestive conclusions must be taken very cautiously as these instruments are in most cases used in combination with each other and their effects are only captured by dummy variables, making it difficult to draw inferences on their individual effects. However they are consistent with the casual observation that technical requirements can be easily manipulated by special interests, and suggest that broad reliance on a change of tariff classification as a one-size-fits-all origin criterion would be a more desirable direction to go.

\section{Administrative Costs}

An alternative to the above is to use the R-index to carry out a non-parametric estimation of upper and lower bound estimates following inspiration from early work by Herin (1986) for EFTA. Table 4 summarizes the results of an exercise in Cadot et al. (2006b). By revealed preference, for headings with $u_{i}=100 \%$, the average preference margin, $\bar{\tau}_{i}$, is an upper-bound, $c_{U}^{C}$, for compliance costs (as $c_{i}^{C}$ 
Table 4. Compliance Cost Estimates (percentage of unit costs)

\begin{tabular}{|c|c|c|c|}
\hline & & PANEURO & NAFTA \\
\hline & Row & Average $\tau_{i}$ & Average $\tau_{i}$ \\
\hline & & \multicolumn{2}{|c|}{ Total Compliance Costs $\left(c^{C}\right)$} \\
\hline$u_{i}=0$ & 1 & $c_{L}^{C}=\bar{\tau}_{i}=4.7$ & $c_{L}^{C}=\bar{\tau}_{i}=0.3$ \\
\hline $0<u_{i}<1$ & 2 & $\bar{c}=\bar{\tau}_{i}=7.2$ & $\bar{c}=\bar{\tau}_{i}=6.2$ \\
\hline \multirow[t]{2}{*}{$u_{i}=1$} & 3 & $c_{U}^{C}=\bar{\tau}_{i}=8.2$ & $c_{U}^{C}=\bar{\tau}_{i}=7.1$ \\
\hline & & \multicolumn{2}{|c|}{ Distortionary cost $\left(c^{D}\right)$} \\
\hline$R_{i} \leq 2 \& u_{i} \geq 95 \%$ & 5 & $c^{D}=\bar{\tau}=3.8$ & $c^{D}=\bar{\tau}=4.4$ \\
\hline \multirow[t]{3}{*}{$R_{i} \leq 2 \& u_{i} \geq 90 \%$} & 6 & $c^{D}=\bar{\tau}=3.9$ & $c^{D}=\bar{\tau}=4.3$ \\
\hline & & \multicolumn{2}{|c|}{ Administrative cost estimate $\left(c^{D}\right)$} \\
\hline & 7 & $\begin{array}{l}c^{D}=\bar{c}-c_{U}^{D}=7.2-3.8=3.4 \\
c^{D}=\bar{c}-c_{U}^{D}=7.2-3.9=3.3\end{array}$ & $\begin{array}{l}c^{D}=\bar{c}-c_{U}^{D}=6.2-4.4=1.8 \\
c^{D}=\bar{c}-c_{U}^{D}=6.2-4.3=1.9\end{array}$ \\
\hline$\tau_{i}=0 \&$ Request $^{\mathrm{c}}$ & 8 & \# 691 lines $^{\mathrm{a}}$ & \# 1089 lines $^{\mathrm{b}}$ \\
\hline$\tau_{i} \leq 3 \% \&$ Request $^{\mathrm{c}}$ & 9 & \#2173 lines $^{\mathrm{a}}$ & \# 1972 lines $^{\mathrm{b}}$ \\
\hline
\end{tabular}

Source: Cadot et al. (2006b) Table 6.

Notes: Data for NAFTA refer to Mexican exports to the US for 2001. Data for PANEURO refer to request by ACP countries for Cotonou status (data for GSP countries were not used because EBA status was only in place since 2001 ). Trade-weighted estimates.

${ }^{\text {a}}$ Total number of tariff lines (at HS-6 digit): 19720

${ }^{\text {b}}$ Total number of tariff lines (at HS-6 digit): 3555

'Only for PANEURO

cannot be greater than the preferential margin, $\tau_{i}$ ). Likewise, for headings with $u_{i}=$ $0 \%$, the preference margin gives a lower-bound estimate, $c_{L}^{C}$. For the remaining sectors with $0 \%<u_{i}<100 \%$, assumptions must be made. One could argue that, heterogeneity of firms notwithstanding, firms would be indifferent to exporting under the preferential regime. Then, an approximation of compliance costs would be given by the average rate of tariff preference computed for the remaining sectors, i.e. on the sample $0 \%<u_{i}<100 \%$. Applying this reasoning, we obtain the estimates in rows 1-3 in Table 4.

The R-index can then be used to breakdown the administrative cost component in total compliance costs. Ignore rents, i.e. $\left(\mu_{i}=0\right)$ so that total compliance costs, $c^{C}$, are given by $c_{i}^{C}=c_{i}^{D}+c_{i}^{A}$, both expressed as a percentage of unit price. Assume that administrative costs would be negligible for firms on their 
participation constraint, i.e. for $\left(0 \%<u_{i}<100 \%\right)$, provided that firms would also be confronted with low values of $r_{i}$, i.e. values corresponding to a change of tariff classification at the subheading level, CS. This corresponds to $r_{i} \leq 2$ (not much paperwork is involved in "proving" a change of subheading). Hence, calculating preference margins for utilization rates close to $100 \%$ (say $u_{i}=95 \%$ or $u_{i}=90 \%$ to be on the safe side when $\left.r_{i} \leq 2\right)$, gives an upper bound of the distortionary component, $c_{i}^{D}$. These estimates are given in row 7 .

As noted by Cadot et al., the rather large differences between the PANEURO and NAFTA estimates, especially when using unweighted data, suggest caution in interpreting these estimates since too much weight is probably given to outlier observations with small trade volumes. Nonetheless, the higher estimates for the EU are coherent with likely higher administrative costs (perhaps associated with certification), and ultimately with lower utilization rates.

The estimates in Table 4 indicate the difficulty of coming up with plausible estimates of the costs of $\mathrm{RoO}$, whether one relies on parametric or non-parametric methods. For example, how should one interpret the number of requests for preferential status in rows 8 and 9 when tariff preferences are nil? Negligible administrative costs?. Or if administrative costs are non-negligible, then neither should one observe requests for preferential status when preferential margins are low, here assumed to be $\tau_{i}=3 \% .^{9}$ In any case, even if there is much hetero-geneity in the data, administrative costs are not negligible, justifying the proposal to do away with origin requirements for preferential margins below an amount around 5\%.

\section{Market power}

To get a handle on the welfare effects of $\mathrm{RoO}$, one has to factor in the rent element associated with preferences and their distribution between the exporting and importing country. This implies estimating the pass-through effect of tariffs on consumer prices (i.e. the extent to which preferences translate into a higher producer price for exporters). Olarreaga and Özden (2005) for AGOA preferences, and Özden and Sharma (2006) for CARICOM preferences estimate that between one-third and one half of tariff reductions are passed on to producers. However, part of the border price increase could just reflect an increase in the complying costs discussed above. Cadot et al. (2005) link the pass-through effects of preferences to Mexican producers in the Textiles \& Apparel sector under NAFTA

\footnotetext{
${ }^{9}$ Using threshold estimation techniques, Manchin (2004) estimates for the same data that preferential status is not asked when $\bar{\tau}_{i}<3-4 \%$
} 
directly to rules of origin, and show that once one takes into account RoO, the pass-through effect falls from $80 \%$ to about $50 \%$. They also show that US producers of intermediates are able to retain a substantial share of the rents generated by Mexican tariff preferences. They conclude that in North-South PTAs where the preferential margin in the Northern partner are rather low, it is likely that RoO are less a development tool to prevent screwdriver assembly than a circuitous way of raising the profits of upstream producers by creating a captive market for them in partner countries.

At this stage, AFTA integration has been mostly geared towards supplying products to the outside world, so the rent transfer associated with preferential access has not been an issue. However, as preferential access is bound to increase with the current FTAs under negotiation involving Japan and Korea with AFTA members, protectionist pressures will increase. A pattern of vertical trade along the lines described here would then be likely to emerge between the richer and poorer members in the PTA and the distribution of rents might be mostly tilted towards the more developed partner.

\section{Value Content Rules and Preference Utilization: Estimates from the EU Preferential Market Schemes}

Currently AFTA has a VC rule. How restrictive is this rule, and how might utilization rates react to a change in the $\mathrm{VC}$ rate from the current maximum limit of $60 \%$ for non-originating imports to a lower (or higher) rate? We draw here on the EU data to estimate what these effects might be. As explained below, because of the great heterogeneity in the data, we confine our estimates to tariff lines that rely on a VC rate as the only PSRO.

Table 5 describes the distribution of the minimum local value content ${ }^{10}$ when this criterion is applied along with the distribution of minimum threshold values. Currently minimum originating value ranges from $50 \%$ to $85 \% .{ }^{11}$ There is

\footnotetext{
${ }^{10}$ In fact, under the current PSRO, the criterion is specified as maximum non-originating imports expressed as a percentage of the 'ex-works factory price', i.e. of unit price at the factory. Since the EU is currently considering a move towards a simplification of RoO procedures that might result in a single criterion requiring a minimum originating value, we have expressed here this criterion in terms of minimum originating value.

${ }^{11}$ For the wholly obtained criterion, originating value has to be $100 \%$. Since this criterion only applies to agricultural products and is not relevant to the AFTA context, is it not considered here.
} 
Table 5. Value-Content Requirements in EU PTAs ${ }^{\mathrm{a}}$ and utilization rates

\begin{tabular}{ccccc}
\hline${\text { RVC } \text { rate }^{\mathrm{b}}}^{\mathrm{F}}$ & Frequency & Percent & $u_{i}(\mathrm{GSP})^{\mathrm{d}}$ & $u_{i}(\mathrm{ACP})^{\mathrm{d}}$ \\
\hline 50 & 4,000 & 20.55 & $38 \%(2.6)$ & $42 \%(2.6)$ \\
60 & 14,185 & 72.89 & $16 \%(1.1)$ & $18 \%(2.7)$ \\
70 & 213 & 1.09 & $53 \%(2.3)$ & $29 \%(3.0)$ \\
80 & 1,012 & 5.20 & $50 \%(2.9)$ & $93 \%(4.3)$ \\
85 & 52 & 0.27 & $44 \%(3.6)$ & $0 \%(3.7)$ \\
Total & 19,642 & 100 & N.A. & N.A. \\
$\tau_{i} \geq 5 \%^{\mathrm{c}}$ & & & $36 \%$ & $34 \%$ \\
$\tau_{i} \geq 10 \%^{\mathrm{c}}$ & & & $34 \%$ & $58 \%$ \\
\hline
\end{tabular}

${ }^{\mathrm{a}}$ Frequency rates are for tariff lines where value-content criterion is the sole criterion for obtaining origin ${ }^{b}$ The Figures in the column indicate the minimum regional value content to satisfy the sufficient processing threshold

'From Table 2

${ }^{\mathrm{d}}$ Utilization rate and average preference rate in parenthesis

bunching around the $60 \%$ value but there is still some variation in VC rates across tariff lines, giving hope that the data will enable identification of the effects of variations in $\mathrm{VC}$ rates on utilization rates. The Table shows that utilization rates are usually higher for ACP than for GSP, with large variations in utilization rates in spite of relatively small variations in preferential margins that are quite low. For AFTA, the closest VC rate is the $50 \%$ RVC rate where the utilization rate is around $40 \%$ for a preferential margin of $2.6 \%$.

Following the discussion in section 3.1, assume that the profit rate for product line $i, \pi_{i}$ is an increasing function of the preferential margin, $\tau_{i}$, and a decreasing value of the originating value content, $v c_{i}$ :

$$
\pi_{i}=\alpha_{0}+\alpha_{1} \pi_{i}+\beta_{1} v c_{i}+\varepsilon_{i}
$$

where the anticipated signs for the parameters or interest are: $\tilde{\alpha}_{1}>0 ; \tilde{\beta}_{1}<0$. There is no observable measure of this benefit, so it is a "latent variable". What is observed instead is the utilization rate, $u_{i}$ which obeys the following law:

$$
u_{i}= \begin{cases}0 & \text { if } \pi_{i}<\pi_{0} \\ f\left(\pi_{i}\right) & \pi_{0}<\pi_{i}<\pi_{1} \\ 1 & \text { if } \pi_{1}<\pi_{i}\end{cases}
$$

for some function $f$ and bounds $\pi_{0}$ and $\pi_{1}$. These bounds, which are not known, 
can be thought of as values of the preferential treatment's net benefit that are respectively so low $\left(\pi_{0}\right)$, and so high $\left(\pi_{1}\right)$, that all firms (heterogeneity across firms is ignored) in the sector end up making the same decision (using or not using the preferential treatment). For simplicity, assume a linear form for $f$, so that $u_{i}$ follows (0.7) in the range where it is not "censored" at zero or one. This leads to the model:

$$
\begin{array}{ll}
u_{i}^{*}=\alpha_{0}+\alpha_{1} \pi_{i}+\beta_{1} v c_{i}+\varepsilon_{i} \\
u_{i}=0 & \text { if } u_{i}^{*} \leq 0 \\
u_{i}=u_{i}^{*} & \text { if } 0 \leq u_{i}^{*} \leq 1 \\
u_{i}=1 & \text { if } u_{i}^{*} \geq 100
\end{array}
$$

where $u_{i}^{*}$ is the latent utilization rate and $u_{i}$ is the observed one.

Turning to the estimation of (0.9), to avoid giving excessive weight to tariff lines with small trade flows, tariff preferences were aggregated using imports as weights from the HS- 8 to the HS- 6 level where the value content rates are specified. In addition, to minimize measurement error, we took an average of utilization rates over the whole period for which data were available (2002 to 2004) and we considered separately GSP (including EBA) beneficiaries and ACP beneficiaries because of the systematically differential utilization rates detected in Table 2 and Figure 1. As mentioned above, to reduce the effects of omitted variable bias, we only considered tariff lines where VC was the only criterion used. Again, this would correspond most closely to the current RoO in Asian PTAs. Finally because of administrative costs, we also restricted our estimates to tariff lines with preferential margins in excess of $2 \%$ or $5 \%$.

The results appear in Table 6 . The overall fit for the models summarized in the likelihood-ratio values are reasonable (see row 6). Average estimated values for preferences rates appear in row 9 and for utilization rates in row 10. Note that the utilization rates are low for these tariff lines, suggesting that value content criteria are rather restrictive. Estimated utilization rates are slightly higher for GSP-eligible countries than for ACP countries. Since estimates are influenced by omitted variables, it is best not to speculate on this small difference in utilization rates across samples.

Turning to the estimates of the individual variables, all signs of estimated coefficients are as expected. Estimates in columns 1 and 4 are carried over the whole sample, with the other columns referring to separate estimates for GSP and 
ACP recipients. Since the variable entered for the VC is the minimum regional value content, the negative sign estimate indicates that, as expected, a higher minimum regional value content lowers utilization rates.

Since coefficients derived from a Tobit estimation indicate the expected marginal effect of the coefficients on the latent utilization rate, $u_{i}$, we computed the expected marginal effect of the $\mathrm{VC}$ on the observed utilization rates, $u_{i}{ }^{12}$. Row 8 translates this estimate into a corresponding change in the estimated utilization rate for a reduction in the maximum regional content from $60 \%$ to $50 \%$. For example, in the case of the GSP estimates in column 2, this reduction would raise the estimated utilization rate by 2.5 percentage point (row 8 column 2 ) from the estimated average of 16.7 percent. The corresponding estimate for the ACP grouping is 8.2 percentage points, an estimate on the high side since it predicts that the utilization rate by more than $50 \%$.

The last three columns report results for a smaller sample including only tariff lines with preference rates exceeding $5 \%$. While the pattern of signs is unchanged, coefficient values often vary by a large margin, suggesting that the estimates are not very stable. Concentrating on the estimated effects of a change in the maximum regional content from $60 \%$ to $50 \%$, one gets the plausible result that utilization rates are less sensible to a change value content rate at tariff lines with higher preference rates.

As a final exercise, the bottom of the Table estimates what utilization rates would be for preferential rates in ACFTA. Chinese and Philippine average MFN tariff rates (row 13 and 15) are used to proxy for the extent of likely preferential market access for ASEAN exports into China and the Philippines, or vice-versa. In this illustrative simulations, the VC is set to the AFTA level (40\% in row 12), which is likely to be the VC rate under ACFTA. Results of this simulation are reported on rows 14 (China) and 16 (Philippines) at the bottom of Table 6. As expected, predicted utilization rates are higher when using the Chinese MFN tariff, which is more than twice higher than the Philippine one.

\footnotetext{
${ }^{12}$ Tobit coefficients are the expected marginal effects of the coefficients on the unobserved $u_{i}^{*}$. Unlike in the classical linear model, they cannot be interpreted directly. Instead, expected marginal effects on the observed $u_{i}$ must be calculated by correcting the tobit coefficients for the censorship. For continuous regressors, the marginal effects are the Tobit function's derivatives and thus give the effect of infinitesimal increases in regressors on the dependent variable. For a binary regressor (dummy variable), the marginal effect gives the effect on the dependent variable of an increase from zero to one in the regressor. Because of the Tobit's nonlinearity, marginal effects vary with the level of all regressors. By convention, they are estimated at their mean values.
} 
Table 6. Determinants of Utilization Rates for EU Preferential Schemes (Tariff lines withValue-Content Rule only)

\begin{tabular}{|c|c|c|c|c|c|c|c|}
\hline & Row & $1(\mathrm{GSP}+\mathrm{ACP})$ & 2 (GSP) & $3(\mathrm{ACP})$ & $4(\mathrm{GSP}+\mathrm{ACP})$ & 5 (GSP) & $6(\mathrm{ACP})$ \\
\hline Dependent varb. & & $u_{i}$ & $u_{i}$ & $u_{i}$ & $u_{i}$ & $u_{i}$ & $u_{i}$ \\
\hline \multirow[t]{2}{*}{ Constant } & 1 & 1.58 & 1.7 & 14.88 & 0.43 & 0.97 & 10.61 \\
\hline & & $(4.52)^{* * *}$ & $(4.99)^{* * *}$ & $(10.68) * * *$ & -1.01 & $(2.36)^{* *}$ & $(6.38)^{* * *}$ \\
\hline \multirow[t]{4}{*}{ (tar. Pref.)(GSP) } & 2 & 0.077 & 0.066 & & 0.05 & 0.026 & \\
\hline & & $(12.74) * * *$ & $(10.89)^{* * *}$ & & $(5.35)^{* * *}$ & $(2.80) * * *$ & \\
\hline & 3 & -0.632 & -0.59 & -4.069 & -0.309 & -0.351 & -2.936 \\
\hline & & $(7.47)^{* * *}$ & $(7.14)^{* * *}$ & $(11.66)^{* * *}$ & $(3.06)^{* * *}$ & $(3.56)^{* * *}$ & $(6.96)^{* * *}$ \\
\hline \multirow[t]{2}{*}{ (tar. Pref.)(ACP) } & 4 & & & 0.043 & & & 0.03 \\
\hline & & & & $(10.00)^{* * *}$ & & & $(6.06)^{* * *}$ \\
\hline Number of Obser. & 5 & 19261 & 13448 & 5857 & 5958 & 4305 & 1697 \\
\hline Likelihood Ratio $^{\text {a }}$ & 6 & $263.43(0)$ & $198.83(0)$ & $222.3(0)$ & $47.48(0)$ & $25.5(0)$ & $71.68(0)$ \\
\hline Sample restriction & 7 & $\left(\tau_{i} \geq 2 \%\right)$ & $\left(\tau_{i} \geq 2 \%\right)$ & $\left(\tau_{i} \geq 2 \%\right)$ & $\left(\tau_{i} \geq 5 \%\right)$ & \multicolumn{2}{|c|}{$\left(\tau_{i} \geq 5 \%\right)\left(\tau_{i} \geq 5 \%\right)$} \\
\hline$r v c_{i}^{1}=r v c_{i}^{0}-10 \Rightarrow \Delta u_{i}$ & 8 & $2.0 \%$ & $2.5 \%$ & $8.2 \%$ & $5.2 \%$ & $1.7 \%$ & 7.9 \\
\hline Mean margin & 9 & 3.74 & 3.79 & 5.09 & 5.14 & 5.22 & 9.78 \\
\hline Mean Utilization Rate & 10 & 0.12 & 0.17 & 0.13 & 0.17 & 0.22 & 0.20 \\
\hline \multirow[t]{2}{*}{ Mean value content } & 11 & 58.8 & 58.9 & 58.6 & 58.2 & 58.6 & 57.5 \\
\hline & \multicolumn{7}{|c|}{ Simulated utilization rates } \\
\hline Assumed value for $r v c_{i}$ & 12 & 40 & 40 & 40 & 40 & 40 & 40 \\
\hline Mean MFN tariff(China) & 13 & 10 & 10 & 10 & 10 & 10 & 10 \\
\hline $\begin{array}{l}\text { Predicted utlilization } \\
\text { rate }\end{array}$ & 14 & 0.32 & 0.37 & 0.45 & 0.25 & 0.28 & 0.40 \\
\hline $\begin{array}{l}\text { Mean MFN tariff } \\
\text { (Philippines) }\end{array}$ & 15 & 4.5 & 4.5 & 4.5 & 4.5 & 4.5 & 4.5 \\
\hline $\begin{array}{l}\text { Predicted utlilization } \\
\text { rate }\end{array}$ & 16 & 0.19 & 0.23 & 0.40 & 0.18 & 0.24 & 0.36 \\
\hline
\end{tabular}

Source: Authors' Computations. See text.

${ }^{a}$ The reported likelihood ratio follows a chi-squared distribution with two degrees of freedom $\left(\chi^{2}(2)\right)$. The p-value of this statistic is reported in brackets.

Because of the very different pattern of trade between the EU and its GSP and ACP partners and the ruling patterns of trade in AFTA, it is difficult to conclude whether these ex-ante simulated utilization rate responses to changes in VC and in preferential margins could be used as guides to the likely effects under AFTA. Furthermore, the estimated coefficients values are sensitive to the choice of 
controls, and the estimates were only carried over the sample of tariff lines where the $\mathrm{VC}$ was the only criterion used to determine origin. Therefore, it is probably best to retain from the exercise that utilization rates could be quite sensitive to changes in $\mathrm{VC}$ requirements and preferential margins.

\section{Lessons from NAFTA and the EU PTAs}

In any preferential trading arrangement (PTA) short of a Customs Union, RoO are necessary to prevent trade deflection. Typically, the vast majority of PTAs use three methods to establish if sufficient transformation or substantial transformation has taken place: (i) change of tariff classification; (ii) a critical threshold for valueadded; and (iii) specific manufacturing processes. The EU and the US use these three methods often relying on multiple requirements at the product level. Taken together, the evidence from the US and EU experience suggests that RoO have indeed restricted access because $\mathrm{RoO}$ have been designed to protect sectors in the EU and the US that would be most affected by preferences. Overall, RoO have been more restrictive than would have been necessary to satisfy the sufficient transformation criterion, with as a consequence low utilization rates in sectors like T\&A where preferential margins were usually high.

The more detailed evidence on the costs of the PSRO in NAFTA and the EU suggests that administrative costs are likely to be non-negligible (though one observes positive imports in tariff lines with zero or small tariff preferences). Distortionary costs created by RoO have even proven harder to quantify, although the low rates of utilization in the textiles and apparel sector attest to their presence. Econometric evidence also shows that, after controlling for the preference margin, utilization rates are lower in sectors characterized by multiple RoO requirements. The econometric evidence also suggests that in the textiles \& apparel sector where vertical linkages are important, $\mathrm{RoO}$ reduce substantially the rent transfer towards exporters which are intended by preferences in the first place. Thus, North-South PTAs, which correspond to those currently under negotiation in the ASEAN, are likely to yield negligible benefits for the low-income partners.

Using a large sample of tariff lines where the sole criterion used was a value content (VC) criterion, the paper estimated utilization rates as a function of preferential margins and $\mathrm{VC}$ rates. The results of the estimation show that higher regional $\mathrm{VC}$ rates are indeed associated with lower utilization rates after controlling for the effects of preferential margins on the utilization rate. A reduction in the 
regional value content from $60 \%$ to $40 \%$ is estimated to increase utilization rates by between 2 and 8 percentage points. If the many uncontrolled other factors influencing utilization rates were the same under the AFTA agreements than under the EU GSP and ACP PTAs, then the current $40 \%$ VC rate might give rise to a utilization rate between $20 \%$ and $40 \%$ depending on the extent of preferential margins.

On the basis of this evidence, this paper has argued that forthcoming regional PTAs in Asia (e.g. ACFTA, Japan-ASEAN and ASEAN_Korea) could well face pressures for shifting to the complex criteria characterizing the EU and US PTAs. These pressures should be resisted, and the ASEAN regional trading agreements under negotiation should stick to the relatively simple current rule requiring a nonoriginating import content of less than $60 \%$ or less of the FOB price of the product under what is in effect full cumulation. If this transparent rule is potentially costly for small firms in poor countries because of its requirements in terms of accounting, it has the advantage of being unambiguous, it bypasses the need for Product-specific Rules of Origin (PSRO) and does not give leeway to lobbying activities by domestic industries over the specification of rules.

\section{Appendix}

\section{A Comparison of NAFTA and PANEURO Rules of Origin ${ }^{13}$}

Virtually all PTAs have regime-wide RoO and Product-specific rules of origin (PSRO). We describe briefly those rules in the case of NAFTA and PANEURO, the two leading countries involved in PTAs. We describe first regime-wide rules, then the PSRO and how these were mapped into the synthetic R-index used in the text.

Regime-wide rules. These usually include: (i) a de minimis (or tolerance) criterion which stipulates a maximum percentage of non-originating materials that can be used without affecting the origin of the final product; (ii) cumulation ${ }^{14}$; (iii) roll-up ${ }^{15}$; (iv) duty-drawback16;(v) certification method. How these regime-wide rules differ between NAFTA, PANEURO (the single list applying to all EU PTAs) and a selection of other PTAs including AFTA is described in Table A1.

Table A1 describes the regime-wide RoO for a representative selection of PTAs. Column 1 shows that virtually all PTAs require PSRO. These typically involve,

\footnotetext{
${ }^{13}$ This appendix draws on Cadot et al. (2006a).
} 
among others, a change of tariff classification (CTC) that can take place at different levels (see Table A2). AFTA here stands out as the exception since it does not use a CTC to confer origin. Like all PTAs, AFTA relies on a regional value content (RVC) criterion. Compared with others, the criterion is relatively lenient. Note also that most PTAs rely on specific manufacturing processes (also known as technical requirements) which apply mostly to trade in textiles and apparel. So far, since most of the production in textiles and apparel in Asia is directed towards the restof-the-world, this criterion has understandably not made its appearance. Finally, again with the exception of AFTA, all PTAs have a tolerance limit (i.e. a percentage of imported inputs that are not counted as non-originating) and an absorption rule. ${ }^{17}$

Product-specific rules (PSRO). Besides regime-wide RoO, PSROs determine eligibility at the tariff-line level. ${ }^{18}$ Two basic criteria are used to determine origin:

\footnotetext{
${ }^{14}$ Cumulation allows PTA producers to import non-originating materials from other PTA member countries without affecting the final product's originating status. Three types of cumulation rules are distinguished: bilateral, diagonal and full cumulation. Bilateral cumulation is most common and applies to trade between two partners in a PTA. It stipulates that producers in country A can use inputs from country B without affecting the final good's originating status provided that the inputs are themselves originating (i.e. provided that they themselves satisfy the area's RoOs). Under diagonal cumulation (the basic principle of the EU's PANEURO system and under AFTA), countries tied by the same PTA can use materials that originate in any member country as if the materials were originating in the country where the processing is undertaken. Finally, under full cumulation, all stages of processing or transformation of a product within the PTA can be counted as qualifying content regardless of whether the processing is sufficient to confer originating status to the materials themselves. It is easy to show that full cumulation allows for greater fragmentation of the production process than the more commonly used bilateral and diagonal cumulation, and hence is less restrictive.
}

${ }^{15}$ The absorption or roll-up principle allows non-originating materials which have acquired origin by meeting specific processing requirements to maintain this origin when used as input in a subsequent transformation. In other words, the non-originating materials are no longer taken into account in calculating value added. The roll-up or absorption principle is used in most PTAs (in particular the EU's GSP and Cotonou), although a few have exceptions for the automotive sector.

${ }^{16}$ Duty drawbacks are refunds to exporters of tariffs paid on imported intermediate inputs. Many PTAs, especially in the Americas, mandate the elimination of duty-drawback schemes for exports to partner countries, on the ground that a duty drawback claimed by a producer in A to export to B would put that producer at a competitive advantage compared to domestic producers in B given that the A-producer already benefits from the elimination of intra-bloc tariffs. The elimination of duty drawbacks as part of a PTA's formation can imply a cut in the profitability of final-good assembly for export to partner countries in the area, although tariff escalation, when present, already provides some protection for final-assembly operations (as it implies lower tariffs on intermediate goods than on final ones).

${ }^{17}$ The PTAs also differ in the way certification is carried out (either single or double certification and either public or private with the option that in some cases such as NAFTA certification needs only be carried out for one shipment rather than all shipments. 
Table A1. Rules of Origin in a Sample Free Trade and Preferential Trade Agreements

\begin{tabular}{|c|c|c|c|c|c|c|c|c|}
\hline & CTC & $\overline{\text { Domesti }}$ & $\begin{array}{c}\text { Value Added } \\
\text { c or Import Content Implied I }\end{array}$ & $\overline{\text { port Content }}$ & $\begin{array}{c}\text { Specific } \\
\text { Manufacturing Process }\end{array}$ & Cumulation & Tolerance & Absor-ption \\
\hline \multicolumn{9}{|c|}{ A. Agreements Involving the EU } \\
\hline PanEuro & Yes $(4,2)$ & & Yes - Import (50-30\%) & $50-30 \%$ & Yes & $\begin{array}{l}\text { Bilateral } \\
\text { Diagonal }\end{array}$ & Yes $10 \%{ }^{\mathrm{b}}$ & Yes \\
\hline GSP & Yes $(4,2)$ & & Yes - Import (50-30\%) & $50-30 \%$ & Yes & $\begin{array}{l}\text { Bilateral } \\
\text { Diagonal }^{\mathrm{a}}\end{array}$ & Yes $10 \%^{\mathrm{b}}$ & Yes \\
\hline EU Cotonou & Yes $(4,2)$ & & Yes - Import (50-30\%) & $50-30 \%$ & Yes & Full & Yes $15 \%^{\mathrm{b}}$ & Yes \\
\hline EU - Chile & Yes $(4,2)$ & & Yes - Import (50-30\%) & $50-36 \%$ & Yes & Bilateral & Yes $10 \%$ & Yes \\
\hline EU - Mexico & Yes $(4,2)$ & & Yes - Import (50-30\%) & $50-30 \%$ & Yes & Bilateral & Yes $10 \%$ & Yes \\
\hline EU - South Africa & Yes $(4,2)$ & & Yes - Import (50-30\%) & $50-30 \%$ & Yes & $\begin{array}{c}\text { Bilateral Diagonal ACP) } \\
\text { Full (SACU) }\end{array}$ & Yes $15 \%$ & Yes \\
\hline \multicolumn{9}{|c|}{ B. Agreements in the Americas and with US } \\
\hline NAFTA & Yes $(2$ & $, 4,6)$ & Yes - Domestic (60-50\%) & $50-40 \%$ & Yes & Bilateral & Yes $7 \%^{\mathrm{b}}$ & $\mathrm{Yes}^{\mathrm{e}}$ \\
\hline Canada - Chile & Ye & & Yes - Domestic (35-25\%) & $75-65 \%$ & Yes & Bilateral & Yes $9 \%$ & Yes \\
\hline US-Israel & & & Yes - Domestic $(35 \%)$ & $65 \%$ & & Bilateral $^{c}$ & Not App & Yes \\
\hline \multicolumn{9}{|c|}{ C. Agreements In Asia/Pacific and with Asian countries } \\
\hline AFTA & & & $\begin{array}{c}\text { Yes - Import } \\
(60 \%)^{\mathrm{d}}\end{array}$ & $60 \%$ & & Diagonal & Not App & \\
\hline ANZERTA & & & $\begin{array}{c}\text { Yes - Domestic } \\
(50 \%)^{d}\end{array}$ & $50 \%$ & & Full & Not App & \\
\hline Sing. - Japan & & Yes $(4)$, & $\begin{array}{c}\text { Yes - Domestic } \\
(60 \%)\end{array}$ & $40 \%$ & Yes & Bilateral & Yes & No \\
\hline Sing.- NZ & & & $\begin{array}{c}\text { Yes - Domestic } \\
(40 \%)^{\mathrm{d}}\end{array}$ & $60 \%$ & & Bilateral & Not App & \\
\hline Singapore - US & & Tes $(2,4,6)$ & $\begin{array}{l}\text { Yes - Domestic } \\
\quad(55-35 \%)\end{array}$ & $65-45 \%$ & Yes & Bilateral & Tes $10 \%{ }^{\mathrm{b}}$ & No \\
\hline
\end{tabular}

${ }^{\mathrm{a}}$ Within Andean, ASEAN, CACM, SAARC only and subject to a 50 per cent value added requirement in the country of export.

${ }^{b}$ alternative rules for textiles and clothing products, often in terms of weight rather than value

${ }^{c}$ up to a maximum of 15 per cent of the value of the product

${ }^{d}$ with the additional requirement that the last stage of manufacture be performed in the exporting country

excluding automotive products

Source: WTO (2002), Brenton (2006) and authors' compilation 
Table A2. PSRO in NAFTA and PANEURO (calculated at the HS-6 level tariff line)

\begin{tabular}{|c|c|c|c|}
\hline \multirow{2}{*}{$\overline{\text { Requirement }}$} & \multirow{2}{*}{$\begin{array}{c}\text { EUROPE } \\
\text { PANEURO }\end{array}$} & \multicolumn{2}{|c|}{ AMERICAS } \\
\hline & & NAFTA & RoO INDEX \\
\hline $\mathrm{NC}$ & 0.39 & 0.54 & 1 \\
\hline $\mathrm{NC}+\mathrm{ECTC}$ & 2.39 & & $1-2$ \\
\hline $\mathrm{NC}+\mathrm{TECH}$ & 1.39 & & 2 \\
\hline $\mathrm{NC}+\mathrm{ECTC}+\mathrm{TECH}$ & 0.00 & & 2 \\
\hline $\mathrm{NC}+\mathrm{VC}$ & 11.46 & & $4-5$ \\
\hline $\mathrm{NC}+\mathrm{ECTC}+\mathrm{VC}$ & 1.57 & & 5 \\
\hline $\mathrm{NC}+\mathrm{VC}+\mathrm{TECH}$ & 0.08 & & 7 \\
\hline NC+WH (CHAPTER) & 7.62 & & 1 \\
\hline NC+WH (HEADING) & 0.70 & & 1 \\
\hline SUBTOTAL & 25.60 & 0.54 & \\
\hline \multicolumn{4}{|l|}{$\mathrm{CI}$} \\
\hline $\mathrm{CI}+\mathrm{ECTC}$ & & 0.02 & 1 \\
\hline \multicolumn{4}{|l|}{$\mathrm{CI}+\mathrm{TECH}$} \\
\hline \multicolumn{4}{|l|}{$\mathrm{CI}+\mathrm{ECTC}+\mathrm{TECH}$} \\
\hline \multicolumn{4}{|l|}{$\mathrm{CI}+\mathrm{VC}$} \\
\hline $\mathrm{CI}+\mathrm{ECTC}+\mathrm{VC}$ & & 0.02 & 2 \\
\hline \multicolumn{4}{|l|}{$\mathrm{CI}+\mathrm{VC}+\mathrm{TECH}$} \\
\hline SUBTOTAL & 0.00 & 0.04 & \\
\hline $\mathrm{CS}$ & 0.20 & 1.29 & 2 \\
\hline CS+ECTC & 0.00 & 2.52 & 2 \\
\hline $\mathrm{CS}+\mathrm{TECH}$ & 1.90 & 0.04 & 2 \\
\hline $\mathrm{CS}+\mathrm{ECTC}+\mathrm{TECH}$ & 0.00 & 0.40 & 2 \\
\hline $\mathrm{CS}+\mathrm{VC}$ & 0.27 & & 3 \\
\hline $\mathrm{CS}+\mathrm{ECTC}+\mathrm{VC}$ & 0.00 & 0.10 & 3 \\
\hline $\mathrm{CS}+\mathrm{VC}+\mathrm{TECH}$ & 0.00 & & 3 \\
\hline $\mathrm{CS}+\mathrm{ECTC}+\mathrm{VC}+\mathrm{TECH}$ & 0.00 & & 3 \\
\hline SUBTOTAL & 2.37 & 4.35 & \\
\hline $\mathrm{CH}$ & 32.99 & 17.09 & 4 \\
\hline $\mathrm{CH}+\mathrm{ECTC}$ & 4.60 & 19.18 & 4 \\
\hline $\mathrm{CH}+\mathrm{TECH}$ & 0.00 & 0.02 & 4 \\
\hline $\mathrm{CH}+\mathrm{ECTC}+\mathrm{TECH}$ & 6.66 & 0.14 & 4 \\
\hline $\mathrm{CH}+\mathrm{VC}$ & 13.01 & 3.54 & 5 \\
\hline $\mathrm{CH}+\mathrm{ECTC}+\mathrm{VC}$ & 0.37 & 0.58 & 5 \\
\hline $\mathrm{CH}+\mathrm{VC}+\mathrm{TECH}$ & 0.00 & 0.10 & 5 \\
\hline $\mathrm{CH}+\mathrm{ECTC}+\mathrm{VC}+\mathrm{TECH}$ & 0.02 & & 5 \\
\hline SUBTOTAL & 57.65 & 40.65 & \\
\hline $\mathrm{CC}$ & 2.16 & 30.95 & 6 \\
\hline $\mathrm{CC}+\mathrm{ECTC}$ & 1.02 & 17.71 & 6 \\
\hline $\mathrm{CC}+\mathrm{TECH}$ & 0.04 & 0.02 & 6 \\
\hline $\mathrm{CC}+\mathrm{ECTC}+\mathrm{TECH}$ & 11.02 & 5.76 & 6 \\
\hline $\mathrm{CC}+\mathrm{VC}$ & 0.00 & & 7 \\
\hline $\mathrm{CC}+\mathrm{ECTC}+\mathrm{VC}$ & 0.00 & & 7 \\
\hline $\mathrm{CC}+\mathrm{VC}+\mathrm{TECH}$ & 0.00 & & 7 \\
\hline $\mathrm{CC}+\mathrm{ECTC}+\mathrm{VC}+\mathrm{TECH}$ & 0.00 & & 7 \\
\hline SUBTOTAL & 14.24 & 54.44 & \\
\hline TOTAL & 100 & 100 & \\
\hline Sources: Anson, Cadot, E & archudur $(200$ & le 1) & \\
\hline
\end{tabular}

$\mathrm{NC}=$ No change; $\mathrm{ECTC}=$ exception to change of tariff classification; $\mathrm{TECH}=$ technical requirement; $\mathrm{VC}=$ value content; $\mathrm{CI}=$ Change of item; $\mathrm{CS}=$ change of subheading; $\mathrm{CH}=$ change of heading; $\mathrm{CC}=$ change of chapter

${ }^{a}$ The index $r_{i}$ is calculated at the HS- 6 level following Estevadeordal (2000) and takes a value in the range $1<r_{i}<7$, a higher value indicating a more restrictive RoO (see text). 
the "wholly obtained" (WH) and "substantial transformation" criteria. The first criterion applies mainly to products which have been entirely grown, extracted from the soil or harvested within the country of export, or manufactured there from any of these products. Therefore it applies when only one country enters into consideration in attributing origin.

The second criterion, "substantial transformation", is more complex and is used for all tariff lines representing products with processing. It involves either of the following alternatives (which can be used as stand-alone but usually in combination with each other):

- Change of Tariff Classification (CTC), requiring the product to belong to a tariff classification different from that of its imported inputs. The change of tariff classification can be expressed at various levels of aggregation: from broader to narrower, chapter (HS 2 digits), heading (HS 4 digits), subheading (HS 6 digits), or item (HS 8 digits). Changes of classification expressed at broader levels of aggregation are, in principle, more constraining. ${ }^{19}$

- Regional Value Content (VC) requirement, requiring the product either to acquire a minimum percentage of local value added in the exporting country or not to exceed a maximum percentage of foreign (non-originating) materials. The VC criterion is largely used by the EU, but not much by the US.

- Technical Requirement (TECH), requiring the product to undergo certain manufacturing operations in the exporting country or prohibiting the use of certain inputs.

- Exceptions (EXC) can be attached to a particular CTC, which prohibits the use of non-originating materials from a certain subheading, heading, or chapter.

- Allowances, on the contrary, permit the use of non-originating materials from certain classifications.

The complexity of regime-wide rules is extended to the PSRO. Table A2

\footnotetext{
${ }^{18}$ The Harmonized Commodity Description and Coding System, commonly known as "HS Nomenclature", is an international multipurpose nomenclature elaborated under the auspices of the World Customs Organization. Although only 116 countries are Contracting Parties to this Convention, more than 190 administrations worldwide apply the US nomenclature, mostly to set up their national customs tariff and for the collection of economic statistical data. The HS Nomenclature comprises 20 sections further subdivided into 96 chapters (commodity group identified by 2-digit code). Chapters are subdivided into headings (4-digit codes) and subheadings (6-digit codes, about 5000 of them), where the harmonization stops. Some administrations such as Eurostat use finer (up to 10 digits) classifications.

${ }^{19}$ Examples of required changes of tariff classification are given in Annex 2.
} 
describes the PSRO for NAFTA and for all the EU PTAs. The criteria correspond to those described in Table 1 in the text, but it is completed by the value attached to the R-index in the last column. The third column gives the value of a restrictiveness index $r_{i},\left(1 £ r_{i} £ 7\right)$ for each type of restriction which is then used to construct an overall index or restrictiveness for the regime (R-index). It is this ordinal index that is used in the discussion in section 2 .

In brief, the "observation rule" is based on the following two assumptions. The first is that the restrictiveness of a change of Tariff Classification (CTC) can be ranked in terms of its restrictiveness on the basis of the following observation: A change of classification at the chapter level (CC) has to be more difficult to satisfy than a change at the Heading $(\mathrm{CH})$ level; likewise, a change at the heading level has to be stricter than at the subheading (CS) level, and a change at the subheading level more stringent than at the tariff line or item level (CI). This implies that the following observation rule (larger values corresponding to more restrictiveness):

$$
\Delta C C>\Delta C H>\Delta C S>\Delta C I
$$

The second assumption is that more criteria usually imply a more restrictive rule. Thus, if a CTC is widely used in both NAFTA and PANEURO, in the majority of cases, it is almost always accompanied by other criteria to be met to confer origin. All but allowances make it more difficult to satisfy origin, so the observation rule assigns higher values to the index resulting from the CTC when these other requirements are added on (and a lower value when there is an allowance). Further details on the construction of the R-index (computed for 3'555 tariff lines for NAFTA and 5'595 tariff lines for PANEURO) are given in Cadot et al. (2006a).

\section{Acknowledgments}

An earlier version of the paper was presented at the Boao Forum for Asia (BFA) "Regional Workshop on the Importance of Rules of Origin and Standards in Regional Integration" held in Hainan on June 27-28. We thank Paul Brenton, Antoni Estevadeordal, Céline Carrère, Bolormaa Tumurchudur and workshop participants for helpful comments on an earlier draft. 


\section{References}

Anson, J., O. Cadot, C. Carrère, A. Estevadeordal, J. de Melo, and B. Tumurchudur, (2005), "Rules of Origin in North-South Preferential Trading Arrangements with an Application to NAFTA", Review of International Economics, .

Antkiewicz, A. and J. Whalley, (2004), "China's New Regional Trade Agreements", NBER \#10992

Baldwin, R. (2006), "Managing the Noodle Bowl: The Fragility of East Asian Regionalism", CEPR DP\# 5561.

Banda, O.G. and J. Whalley, (2005), "Beyond Goods and Services: Competiton Policy, Investment, Mutual Recognition, Movement of Persons, and Broader Cooperation Provisions of Recent FTAs Involving ASEAN Countries" NBER \#11232.

Brenton, P., (2006),"Notes on Rules of Origin with Implications for Regional Integration in South East Asia", mimeo, World Bank

Brenton, P. and M. Manchin (2003), "Making EU Trade Agreements Work: The Role of Rules of Origin", The World Economy, 26.

Brenton, P. and H. Imagawa, (2005), Rules of Origin, Trade and Customs", in L de Wulf and J. Sokol eds,

Cadot, O., A. Estevadeordal, A. Suwa-Eisenmann and Thierry Verdier eds. (2006) The Origin of Goods: Rules of Origin in Regional Trade Agreements, Oxford U. Press

Cadot, O., C. Carrère, J. de Melo, A. Portugal-Perez (2005), "Market Access and Welfare Under Free Trade Agreements: The case of Textiles under NAFTA", World Bank Economic Review, 19(3), 379-405. (also CEPR DP\#5051)

Cadot, O., A. Estevadeordal, A. Suwa-Eisenmann (2006a), "Rules of Origin as Export Subsidies", in O. Cadot et al. eds., pp. 149-72

Cadot, O., C. Carrère, J. de Melo and B. Tumurchudur (2006b) "Product Specific Rules of Origin in EU and US Preferential Trading Arrangements: An Assessment", World Trade Review, 199-225 (also CEPR DP\#4998)

Cadot, O., J. de Melo and E. Pondard (2006c) "Evaluating the Consequences of a Shift to a Value-added method for Determining Origin in the European Union's GSP Preferential Scheme" report prepared for the EC Commission

Carrère, C., and J. de Melo (2006), "Are Different Rules of Origin Equally Costly? Estimates from NAFTA" chp. 7 in O. Cadot et al. eds., 191-212.

Dixit, A. and G. Grossman (1982), "Trade and Protection with Multistage Production", Review of Economic Studies, 49, 583-94.

Erasmus, H., F. Flatters, and R. Kirk (2006), "Rules of Origina as Tools of Development? Lessons from SADC" in O. Cadot et al. eds, 259-94.

Estevadeordal, A. (2000), "Negotiating Preferential Market Access: the Case of NAFTA", Journal of World Trade, 34(1), 141-66

Estevadeordal, A. and K. Suominen (2006), "Mapping Rules of Origin Around the World" chp. 3 in O. Cadot et al. eds, pp. 69-113. 
Herin, Jan (1986), "Rules of Origin and Differences between Tariff Levels in EFTA and in the EC"; EFTA Occasional Paper 13.

Krishna, K., (2006), "Understanding Rules of Origin”, chp. 1 in O. Cadot et al. eds., pp. 19-34.

Manchin, M. (2004), "Preference Utilization and Tariff Reduction in EU Imports from ACP Countries", mimeo, Tinbergen Institute.

Olarreaga, M. and C. Özden (2005), "AGOA and Apparel: Who Captures the Tariff Rent in the Presence of Preferential Market Access?", World Economy, 28(1), 63-77.

Özden, C. and G. Sharma (2006), "The Effects of Preferential Market Access: Caribbean Basin Initiative and the Apparel Sector", World Bank Economic Review, 20(2), 24160.

Sanyal, K.K. and R. Jones (1982), "The Theory of Trade in Middle Products", American Economic Review, 72, 16-31.

World Bank (2005), "Global Economic Prospects 2005: Trade, Regionalism and Development"

WTO (2002), "Rules of Origin in Regional Trade Agreements", WT/REG/W/45

Wulf, L. de, and J. Sokol (2004) eds., Customs Modernization: A Handbook, World Bank. 